\title{
Partnering for Education and Career Development of Librarians and Information Specialists
}

\author{
Ruth HOLST M.S.L.S ${ }^{\mathrm{a}, 1}$

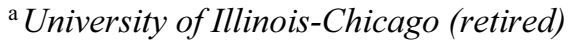

\begin{abstract}
Donald A.B. Lindberg M.D. was a strong proponent of self-improvement for all professions. He believed it was imperative for health sciences librarians to embrace lifelong learning as the Internet and networked information radically changed their work and opened new opportunities to increase their scope and impact. During Dr. Lindberg's 1984-2015 tenure as its Director, the U.S. National Library of Medicine (NLM) became an even more dominant influence on education and career development of health sciences librarians. This chapter focuses on the way NLM partnered with other institutions and organizations to ensure that education and training were consistently part of the roll-out of new NLM programs and services as they were implemented.
\end{abstract}

Keywords. Donald A.B. Lindberg M.D., U.S. National Library of Medicine, Education and Training, Medical Library Association, National Network of Libraries of Medicine

\section{Introduction}

When Donald A.B. Lindberg M.D. took over as Director of the U.S. National Library of Medicine (NLM) in 1984, NLM programs were directed primarily at health professionals and scientists, with librarians serving as the intermediaries to NLM systems and services. Beginning in 1966, NLM's Associate Fellows Program provided a yearlong experience for librarians that continues to the present day. A large component of NLM's involvement in direct training of health sciences librarians began following passage of the Medical Library Assistance Act (MLAA) in 1965. Although it authorized funds for masters-level education, the MLAA mandate to establish the Regional Medical Library (RML) Network had a longer-term impact on training of librarians. As NLM launched new services, such as the MEDLINE retrieval system in 1971, it worked with and through the Network to provide hands-on training for librarians as the logical strategy to make sure these services were used effectively.

Dr. Lindberg not only continued the emphasis on professional development for librarians, but greatly enhanced opportunities as part of the NLM's planning and development processes. Dr. Lindberg was a strong proponent of self-improvement through continuing education for all professions, and in his presentation to the $7^{\text {th }}$

\footnotetext{
${ }^{1}$ Corresponding Author, Ruth Holst, 645 N. Kingsbury St., Apt. 1709, Chicago, IL 60654, USA; Email:holstruth@gmail.com
} 
International Congress on Medical Librarianship in 1995, he spoke about the growing pains faced by libraries and librarians attributable to the influence of the Internet on their work. He urged librarians to "embark on a program of lifelong learning that will enable them to make optimum use of the advantages offered by modern technology" [1].

\section{Librarians and the NLM - A Balancing Act}

The relationship between the National Library of Medicine and the health science library community has evolved over the years and is well-described in Betsy Humphreys' 2001 Janet Doe Lecture for the Medical Library Association [2]. Humphreys illustrated how program decisions and new services at NLM had an enormous impact on health sciences libraries and librarians. For the most part, being able to tap into the extensive resources and expertise of the NLM gave medical librarians a leg up over their colleagues in other types of libraries. But this did not prevent librarians from expressing their concerns over NLM decisions which had an impact on their daily work lives.

It is impossible to describe the influence of Dr. Lindberg on the education and training of medical librarians and other information specialists without looking at the partnerships that NLM forged with academic institutions around the country and with professional associations. While many of these organizations had a relationship with NLM before Dr. Lindberg arrived on the scene, the nature and strength of those relationships changed. Academic health centers and their libraries are an essential link to NLM's impact on the education of librarians. Through their roles as regional medical libraries and resource libraries within the RML Network (renamed the National Network of Libraries of Medicine in 1991) and their coordinated efforts within the Association of Academic Health Sciences Libraries (AAHSL), these libraries provided education and training for not only their own staff, but for librarians and health information specialists throughout their communities.

The Medical Library Association (MLA), which represents professionals from health sciences information centers of all types and sizes, was and is the predominant provider of continuing education for librarians working in academic medical centers, community hospitals, nursing colleges, pharmaceutical companies, and a vast array of public health and non-profit health agencies. From 1964-1987, MLA had a formal structure in place in the form of the MLA-NLM Liaison Committee and used that link to expand and enhance its working relationship with NLM to the benefit of both organizations. In the agreement to disband the Committee in favor of special meetings when matters of substance arose, the MLA Board committed to reserving at least one hour of each annual meeting for an NLM Update. Throughout his tenure, Dr. Lindberg was a regular attendee at MLA annual meetings and lead speaker at the NLM Update sessions.

Partnerships between NLM and the library community proved to be highly beneficial over the years for the career development of health sciences librarians, but the relationship ran into some challenges along the way [2]. Several NLM initiatives during Dr. Lindberg's first years as Director set the stage for potential conflict between NLM and the library community. For example, in 1986, the Grateful Med search software was introduced as an interface that would enable individuals without search training to access the MEDLINE database [3]. Grateful Med was an evolutionary step because it opened NLM databases to remote individual users who might not have an affiliation with a hospital or medical center library. 
In its enthusiasm to get the word out about the new user-friendly software, NLM inadvertently set off a controversy within the library community in 1989. A letter signed by Dr. Lindberg and sent to hospital administrators informing them about Grateful Med, failed to mention librarians or library services. In my own hospital, the letter was forwarded to me by my administrator and used as an opportunity to talk about this new access to MEDLINE. In many libraries, however, the development and promotion of services designed for direct use by health professionals was seen as an effort to bypass librarians and to downplay their expertise as intermediaries between end-users and database services. Librarians feared they would lose ground if administrators believed that health professionals could search without assistance by trained library professionals. In his 2014 oral history with Linda Watson, Dr. Lindberg gave his alternative view of this conflict. He believed that as amateur searchers, "doctors are not going to be anywhere close to as good searchers as medical librarians, but they'll admire them" [4].

In 1989, the NLM Board of Regents issued an outreach planning report with four recommendations to improve access to NLM information services "by every American health professional in all settings" [5]. This report was based on the work of a blue-ribbon panel (including librarians) chaired by Dr. Michael DeBakey and came to be known as the "DeBakey Report." The report called for NLM and RML network libraries to work together to ensure that information resources are available to all health professionals. It recommended that the RML Network be reconceived as a "field force" for developing, marketing, and distributing NLM products and services. Although the report emphasized the need for librarians to train health professionals to access NLM resources more directly, it also recommended increased funding for new training opportunities for health sciences librarians.

Thanks to the foresight of Dr. Lindberg, new NLM training initiatives brought librarians into partnership with physicians and other health professionals. Ultimately, this helped to promote the inclusion of librarians as equal members on multidisciplinary teams, including those producing comprehensive systematic reviews and meta-analyses on specific subjects.

\section{The Woods Hole Experience}

No other training effort had more impact on the development of librarians' knowledge and skills in the application of computers and information science in medicine than the Woods Hole Medical Informatics course (later the Biomedical Informatics Short Course at Woods Hole, and subsequently Georgia). Initiated by Dr. Lindberg in 1992 in cooperation with the Marine Biological Laboratory in Woods Hole, MA, this competitive training fellowship was funded by NLM and aimed at medical educators, medical librarians, medical administrators, and young faculty who had "the ability to become change agents in their institutions" [6-7]. For many librarians, participation in the weeklong residential informatics short course was the most personal contact they had with Dr. Lindberg and his wife Mary. Course attendance became a badge of honor for many in the profession.

A 2005 survey of a random sample of past participants in the course from 19922001 found $64 \%$ of respondents subsequently were responsible for making strategic health care information-related decisions and $69 \%$ were responsible for training other people to use information technologies, systems, or tools [8]. Participants reported that the course changed their credibility levels and increased their confidence working in the 
field of medical informatics. Taking the course alongside physicians, nurses and other health professionals gave librarians an opportunity to develop their networking skills at the same time they were learning about informatics. Hundreds of librarians benefited from participation in the informatics short course. Many have gone on to be informatics leaders within their institutions and the profession. Others have played the lead role in developing and teaching courses for librarians, medical students, nurses, and other health professionals.

\section{NLM Planning Panel for Education and Training}

As part of its long-range planning process, NLM assembled a planning panel on the education of librarians in 1994, with participation from a multidisciplinary team of health professionals, librarians, library school faculty, medical informaticians, and NLM staff. The resulting 1995 report offered a series of goals focused on four key areas: 1) evolving role of the health science librarian; 2) professional educational programs; 3) lifelong learning programs; and 4) recruitment, including minorities [9]. Woven into the final report was the establishment of "Challenge Awards" to support planning for implementation of specific report recommendations that required further study. During the 1995 U.S. fiscal year, seven awards were made, including to two university medical libraries and five professional library schools [10].

As an example of the impact of these awards, the M.L.S. program at the University of Pittsburgh added a specialization in health sciences librarianship, launched a recruitment plan to attract under-represented minorities, and designed a series of continuing education courses approved by MLA for their Academy of Health Information Professionals certification program [11]. Along with many tangible new programs and courses developed as a result of the challenge grants, the panel's report emphasized that the rapid changes occurring in medical and healthcare informatics required new ways of training in graduate programs and in continuing education for practicing librarians. Preparing librarians to step into new training and liaison roles was part of what was required.

In addition to the challenge grants, NLM took several steps in 1998 to implement the planning panel's recommendations. The NLM Library Associates Program was renamed to emphasize its Fellowship stature and was expanded from four to up to eight participants beginning in September 1998. An optional second year was added so the Associate Fellows could spend a year in an academic medical center, hospital, or other health-related institution. The purpose of the second year was to give librarians experience working with a multidisciplinary team to integrate library and information services into patient care, professional education, or research programs of the parent institution [12].

The panel's report also led to expanding educational opportunities for librarians in biomedical informatics. Beginning in 1998, all existing NLM Informatics Training Programs were offered additional funding and strongly encouraged to offer training through the curriculum suitable to those interested in health sciences libraries. By 1999, librarians were in place at four of the ten Informatics Training Programs. Furthermore, the Applied Informatics Fellowships were widely publicized to the library community as a means of supporting informatics training at a mid-career level. As medical libraries began to play a greater role in supporting researchers in fields such as molecular biology and genomics, there was a need to establish educational and support programs to address 
the challenges their users were facing with all the new databases and retrieval and analysis tools.

Renata Geer M.L.S, a former NLM Associate working in NLM's National Center for Biotechnology Information (NCBI), saw the need for a basic course for librarians and led development of an "Introduction to Molecular Biology Information Resources," first offered in May 1997 as an eight-hour CE course at the MLA annual meeting [13]. Today a 14-week, self-paced course "Bioinformatics and Biology Essentials for Librarians: Databases, Tools, and Clinical Applications" is listed in the NNLM Class Catalog. This current version offers 30 hours of MLA CE credit. Librarians in the sciences have benefited tremendously from educational support provided by NLM to enhance their knowledge of and experience with a wide range of bioinformatics databases and research tools.

\section{Training and Education Within the National Network of Libraries of Medicine}

When Congress passed the MLAA in 1965, it gave NLM authorization and funding for training librarians and mandated establishment of the Regional Medical Library (RML) Network (renamed the National Network of Libraries of Medicine (NN/LM) in 1990). When Dr. Lindberg became the NLM Director in 1984, there were approximately 3,000 libraries in the Network, including academic medical libraries, libraries in hospitals and pharmaceutical companies, and other biomedical libraries. By the time Dr. Lindberg retired in 2015, the NNLM had grown to more than 7,000 members, including public libraries, information centers, and community-based organizations. Dr. Lindberg was a strong proponent of the NNLM and its critical role in bringing information services to health professionals, the general public, and underserved communities [14]. He also championed the role of the NNLM in the career development of health sciences librarians. Thousands of librarians received training either directly or indirectly through the NNLM during the 30 plus years of his tenure.

As MEDLINE and other NLM resources were developed and made available for searching, the training emphasis of the RMLs expanded to include more training for Network member librarians to be effective users of these new databases with a focus on librarians in hospitals, clinics, nursing and allied health professional schools, and public health societies and organizations. By 2001, training services were concentrated into the National Training Center and Clearinghouse (NTCC) at the New York Academy of Medicine. The NTCC later became the NNLM Training Office (NTO) and moved to the University of Utah [15].

With Dr. Lindberg's strong support, training in specialized areas grew as NLM provided additional databases on a wide range of topics. Dr. Lindberg thought network librarians should be knowledgeable about all NLM services, not just MEDLINE and other bibliographic databases. In the 1980s, HIV/AIDS resources began to be incorporated into the training curriculum as did toxicology and environmental topics and in the early 1990s health services research and technology assessment resources.

In the 1990's, as public libraries began to provide Internet services to the community, it became clear that a large percentage of queries coming from the public were health-related. When MEDLINE became free on the Internet in 1997, many of the new users were members of the public. In 1998 NLM launched a pilot project "to learn about the role of public libraries in providing health information to the public and to generate information that would assist NLM and the NNLM in learning how best to work 
with public libraries in the future" [16]. The pilot involved an early version of NLM's MedlinePlus consumer health website to obtain feedback from public library staff and their patrons.

Extra funding was added to the RML contracts to pay for consumer health coordinators in every region and during the 2001-2006 contract period, the NNLM developed a series of four consumer health courses targeted to public librarians. Although directed to public librarians and other community-based information specialists, these courses were often attended by health sciences librarians. The four basic courses became the core curriculum for the MLA Consumer Health Information Specialization (CHIS) described in the next section of this chapter.

Another area in which NLM had an impact on career development and training is emergency preparedness and disaster mitigation. Events such as a 2001 terrorist attack on the World Trade Center in New York City and a series of natural disasters along the southern coasts of the U.S. exposed the need to assure consistent availability of critical health information resources during national and regional emergencies. In the aftermath of Hurricanes Katrina and Rita in 2005, Dr. Lindberg was impressed by the work of NNLM libraries in providing back-up information access for health professionals, faculty, students, and patients and of public libraries in supporting displaced families. He envisioned the NNLM as playing a continuing vital role in this work, and beginning with the 2006-2011 RML contracts, there was a new emphasis on emergency preparedness.

NLM's long-range plan for 2006-2016 called for the NNLM to develop strategies for network libraries to provide back-up services for one another and to conduct training in emergency preparedness and response [17]. By 2008, NLM had launched its Disaster Information Management Research Center (DIMRC) "to make a strong commitment to disaster remediation and to provide a platform for demonstrating how libraries and librarians can be part of the solution to this national problem" [17]. Working with FEMA and other governmental units, DIMRC developed and/or identified a series of basic and advanced level courses aimed at training professionals in multiple fields to access, use, and manage information to support their institutions and communities in planning for, responding to, and recovering from emergencies and disasters [18].

As the incoming president of MLA and a former member of the 2006-2016 long range planning panel, I was keenly aware of the importance Dr. Lindberg placed on having the NLM play a central role in channeling health information resources to communities affected by disasters and also for preparing librarians to take on key responsibilities for managing access to those resources. Thus, I was not surprised to be approached by a member of the DIMRC staff at the 2010 MLA meeting about an NLM/MLA partnership to co-develop the new Disaster Information Specialization (DIS) that is described in the next section of this chapter.

\section{Partnering with the Medical Library Association}

The Medical Library Association (MLA) has been the primary source of continuing education (CE) for health sciences information professionals since the middle of the twentieth century. In the mid-1980s, MLA began to expand its CE program to a fully integrated professional development program. In 1989, MLA appointed a Knowledge and Skills Task Force that conducted a member needs assessment and crafted an educational policy statement, Platform for Change, that described the need for lifelong interdisciplinary learning for the field, provided concrete guidelines for graduate 
programs, and acknowledged the need for a strong continuing partnership between MLA and NLM in attaining the goals of the document [19].

NLM responded to the recommendations in Platform for Change by convening the planning panel that resulted in the 1995 report "The education and training of health sciences librarians" described previously. One of the seven "challenge awards" made (to implement recommendations from the report) went to the University of South Carolina to partner with MLA to conduct a needs assessment of the MLA membership in 1996 to account for the extraordinary technological developments since the previous member survey in 1990. This synergy between NLM and MLA has enabled both organizations to advance educational opportunities for health information professionals that were aligned with common and mutually beneficial goals.

Over the years, MLA and NLM have worked on several collaborative projects and often acted as co-sponsors for the other's programs, including the establishment of the Consumer Health Information Specialization (CHIS) and the Disaster Information Specialization (DIS) mentioned earlier. MLA's CHIS credential, implemented in 2001, was targeted toward medical librarians, public librarians, librarians working in consumer health libraries, allied health professionals, information professionals, and anyone concerned with providing accurate and useful health information to the public at the right time and place. NNLM and MLA worked closely together to promote this education opportunity and provide in-person and online courses, based upon four courses developed by the NNLM. In 2021, MLA reported that more than 1,300 librarians, health and information professionals, and others had earned the CHIS and many more had taken consumer health information courses, another testament to Dr. Lindberg's vision of providing health information to the public [20]. It also has stimulated more librarians to reach out to their communities, participating in health fairs and other community events.

Dr. Lindberg's influence weighed heavily in the decision to develop the DIS credential as a collaborative project between MLA and NLM. Recognizing the untapped potential of libraries, librarians, and information services to aid in the nation's disaster management efforts, DIMRC worked with MLA staff to develop a curriculum that would address the core competencies needed to manage health information resources effectively as part of the national response to major disasters. The curriculum covers key concepts in disaster medicine and the public health field for librarians, as well as health information literacy for the disaster workforce. This specialization has been promoted at conferences and in articles and editorials in both library journals and journals reaching the emergency/disaster workforce, public health departments, and policymakers. As of 2021, nearly 200 people have qualified for DIS certification [20]. It represents an area of training that might not have been established without Dr. Lindberg's leadership and his belief in librarians as a group of professionals well positioned to provide these services.

NLM and MLA also have collaborated on several educational conferences. As a follow-up to the NLM and NNLM pilot project with public libraries in 1998, NLM held a colloquium in 2001 in conjunction with the American Library Association (ALA) midwinter meeting, co-sponsored by the NNLM, MLA and the Public Library Association (PLA), a division of ALA. Entitled "The Public Library and Consumer Health: Meeting Community Needs Through Resource Identification and Collaboration," the program included presentations by Dr. Lindberg and several other NLM staff members [21]. The interaction between public librarians and health sciences librarians was very positive and led to mailings to public libraries in all 50 states, including a letter from Dr. Lindberg and the PLA President, along with bookmarks and 
a poster about MedlinePlus.gov, promoting NLM's free resources available to all libraries.

Other education and career development collaborations between NLM and MLA have taken the form of projects to improve access to educational opportunities. MLA's Educational Clearinghouse, started in 1973, merged with the National Training Center and Clearinghouse (NTCC) Educational Clearinghouse database in 2011 to eliminate the duplication of effort between the two organizations, thereby making it easier for librarians to locate the best CE course for their needs [22]

In order to encourage minority students to choose health science librarianship as a career, the NLM provided funds for several years to "increase the size of MLA's existing minority scholarship, and to support, in partnership with MLA, the ALA's Spectrum Scholars program to attract students of color to graduate programs in library and information studies and for outreach to minority college and high school students" [23].

To demonstrate its commitment to the quality of health through health informationrelated research and to recognize Dr. Lindberg's encouragement of librarian involvement in research, the MLA announced in 2002 that it would establish the Donald A. B. Lindberg Research Fellowship with the goal of building an endowment to award up to $\$ 25,000$ annually for work in pursuit of research related to health sciences libraries and librarianship [24].

In his MLA oral history interview with Linda Watson, Dr. Lindberg commented on his working relationship with Carla Funk, MLA's Executive Director from 1992-2015. He said "I compliment you on Carla Funk, who has been absolutely marvelous, a leader of MLA. We worked so smoothly and without a whole lot of folderol, and even written agreements just naturally supporting what we're trying to do, and we are having some pleasure in supporting what she's trying to accomplish and MLA is after. It has been a great pleasure and a wonderful partnership" [4].

\section{The NLM/AAHSL Leadership Fellows Program}

From a participants' perspective, the NLM/AAHSL Leadership Fellows Program is one of the most valuable collaborations with NLM. The Association of Academic Health Sciences Libraries (AAHSL) is affiliated with the Association of American Medical Colleges (AAMC). It "supports academic health sciences libraries and directors in advancing the patient care, research, education, and community service missions of the academic health centers through visionary executive leadership and expertise in health information, scholarly communication, and knowledge management" [25]. The Leadership Fellows Program was initiated in 2002 through the generous support of NLM and continues to this day with the planning and execution of the program done primarily by AAHSL. The year-long fellowships pair a group of mid-career librarians who have some management experience with mentors who are serving as library directors for AAMC member institutions. Fellows attend a capstone event that includes leaders from NLM, including Dr. Lindberg during his tenure as Director. Participants in the program have overwhelmingly found the experience to have had a positive impact on their career development and their levels of self-confidence. Over a period of 17 years, 92 fellows and 74 mentors have been part of this program, and as of 2019, 54\% (47) of the Fellows had received a permanent director position [26]. 


\section{Conclusion}

Looking back over the more than 30 years when Dr. Lindberg was at the helm, examples abound of the ways NLM enhanced educational opportunities for librarians, some by providing hands-on training specific to a database or resource, and others by providing resources to partnering institutions and organizations to carry out the training. Dr. Lindberg was the prime mover behind some of these opportunities and supported all of them. NLM's outreach efforts led to additional funding for the RML Network which in turn, led to more training for health sciences librarians and increased emphasis on the role that librarians play in ensuring that health professionals in community-based settings can use NLM resources to practice evidence-based medicine. In partnership with the Marine Biological Laboratory in Woods Hole, MA, NLM provided an immersive weeklong medical informatics fellowship for librarians to become more knowledgeable about applications of computers in medicine and to do so alongside health professionals and administrators in order to provide networking opportunities. Under the leadership of Dr. Lindberg, NLM built synergistic relationships with MLA and AAHSL to greatly enhance education and career development opportunities for librarians and information professionals serving health-related institutions and organizations.

\section{References}

[1] Lindberg DAB. The modern library: lost and found. Bull Med Libr Assoc 1996 Jan;84(1):86-90.

[2] Humphreys BL. Adjusting to progress: interactions between the National Library of Medicine and health sciences librarians, 1961-2001. J Med Libr Assoc 2002 Jan;90(1):4-20.

[3] Dorsch JL, Faughnan JG, Humphreys BL. Grateful Med: direct access to MEDLINE for health professionals with personal computers. In: Humphreys BL, Logan RA, Miller RA, Siegel ER, editors. Transforming biomedical informatics and health information access: Don Lindberg and the U.S. National Library of Medicine. Amsterdam: IOS Press; 2021.

[4] Donald A.B. Lindberg, M.D. interview by Linda A. Watson. [Internet] October 31, 2014 [cited 2021 July], transcript, MLA Oral Histories. Medical Library Association, Chicago, IL. Available from: https://www.mlanet.org/blog/lindberg-donald-ab-md

[5] National Library of Medicine (U.S.) Board of Regents. Improving health professionals' access to information: challenges and opportunities for the National Library of Medicine. Bethesda MD: National Library of Medicine: 1989.

[6] National Library of Medicine (U.S.). Programs and services Fiscal Year 1992. [Internet] [cited June]. Available from: https://www.nlm.nih.gov/ocpl/anreports/fy1992.pdf

[7] Cimino JJ. The biomedical informatics short course at Woods Hole/Georgia: training to support institutional change In: Humphreys BL, Logan RA, Miller RA, Siegel ER, editors. Transforming biomedical informatics and health information access: Don Lindberg and the U.S. National Library of Medicine. Amsterdam: IOS Press; 2021.

[8] Patel VL, Branch T, Cimino A, Norton C, Cimino JJ. Participant perceptions of the influences of the NLM-sponsored Woods Hole medical informatics course. J Am Med Inform Assoc 2005 MayJun;12(3):256-62. DOI: 10.1197/jamia.M1662

[9] National Library of Medicine (U.S.) Board of Regents. NLM Planning Panel on the Education and Training of Health Sciences Librarians. The education and training of health sciences librarians. Bethesda MD: National Library Medicine: 1995.

[10] National Library of Medicine (U.S.). Programs and services fiscal year 1996. [Internet] [cited 2021 June]. Available from: https://www.nlm.nih.gov/ocpl/anreports/fy1996.pdf

[11] Detlefson EG, Epstein BA, Michelson P, Detre T. Transforming the present - discovering the future: the University of Pittsburgh's NLM grant on education and training of health sciences librarians. Bull Med Libr Assoc 1996 Oct;84(4):524-33

[12] National Library of Medicine (U.S.). Programs and services fiscal year 1998. [Internet] [cited 2021 June] p.13..Available from: https://www.nlm.nih.gov/ocpl/anreports/fy1998.pdf 
[13] Geer RC. Broad issues to consider for library involvement in bioinformatics. J Med Libr Assoc. 2006 Jul;94(3):286-98, E152-5. PMID: 16888662; PMCID: PMC1525323.

[14] Shipman JP, Burroughs CM, Rambo N. NLM's library network: a force for outreach. In: Humphreys BL, Logan RA, Miller RA, Siegel ER, editors. Transforming biomedical informatics and health information access: Don Lindberg and the U.S. National Library of Medicine. Amsterdam: IOS Press; 2021.

[15] Speaker SL. An historical overview of the National Network of Libraries of Medicine, 1985-2015. J Med Libr Assoc 2018 Apr;106(2):162-74.

[16] Wood FB, Lyon B, Schell MB, Kitendaugh P, Cid VH, Siegel ER. Public library consumer health information pilot project: results of the National Library of Medicine evaluation. Bull Med Libr Assoc 2000 Oct;88(4):314-22.

[17] National Library of Medicine Board of Regents. Charting a course for the $21^{\text {st }}$ century: NLM's long range plan 2006-2016. Bethesda MD: The Library, 2006. p.66.

[18] Love CB, Arnesen SJ, Phillips SJ, Windom RE. National Library of Medicine Disaster Information Management Research Center: achieving the vision, 2010-2013. Information Services \& Use 2014;34:149-170.

[19] Roper FW. The Medical Library Association's professional development program: a look back at the way ahead. J Med Libr Assoc 2006 January 94(1):8-18.

[20] Medical Library Association. Professional development/ specializations. [Internet] [Cited 2021 April]. Available from: https://www.mlanet.org/p/cm/ld/fid=42

[21] National Library of Medicine (U.S.). Programs and services fiscal year 2001. [Internet] [cited 2021 June]. Available from: https://www.nlm.nih.gov/ocpl/anreports/fy2001.pdf

[22] NTCC educational clearinghouse merges with the MLA education clearinghouse. NLM Technical Bulletin 2011 May-June (380):e-1. Available from: https://www.nlm.nih.gov/pubs/techbull/mj11/mj11_ntcc_merger.html

[23] National Library of Medicine (U.S.). Programs and services fiscal year 2000. [Internet] [cited 2021 June]. Available from: https://www.nlm.nih.gov/ocpl/anreports/fy2000.pdf

[24] MLA Annual Meeting proceedings, Carol Jenkins Presidential Address, 2002. [Internet] [Cited 2021 May] Available from: https://www.ncbi.nlm.nih.gov/labs/pmc/articles/PMC141200/

[25] Association of Academic Health Sciences Libraries. About AAHSL. [Internet] [Cited 2021 April]. Available from: https://www.aahsl.org

[26] Association of Academic Health Sciences Libraries. NLM/AAHSL Leadership Fellows Program. 20182019 Report [Internet] [Cited 2021 April]. Available from: https://www.aahsl.org/assets/20192020/Fellows/NLM_AAHSL_LFP_report_2018-2019_FINAL_brief.pdf 